\title{
PENGGUNAAN BAHASA PROKEM PADA MEDIA SOSIAL WHATS APP MAHASISWA UNIVERSITAS MUHAMMADIYAH TANGERANG
}

\author{
Aidil Syah Putra ${ }^{1}$, Bagus Hady Hartanto ${ }^{2}$ \\ Universitas Muhammadiyah Tangerang \\ aidilpoetra@gmail.com ${ }^{1}$ \\ bagushady19@gmail.com ${ }^{2}$
}

\begin{abstract}
ABSTRAK
Tujuan penelitian ini yaitu mendeksripsikan bahasa prokem mahasiswa Universitas Muhammadiyah Tangerang dalam media sosial whats app dan dampak penggunaan bahasa prokem dalam media sosial whats app di kalangan mahasiswa Universitas Muhammadiyah Tangerang. Metode penelitian yaitu Jenis penelitian ini menggunakan metode analisis isi dengan pendekatan deskriptif kualitatif. Pendekatan deskriptif kualitatif dipilih karena peneliti berusaha menyajikan kenyataan-kenyataan secara objektif sesuai dengan kenyataan dalam bentuk kata ataappun kalimat yang ditemukan di lapangan tentang penggunaan bahasa prokem dalam media sosial whats app. Data yang digunakan dalam penelitian ini adalah data tulis yang berasal dari unggahan status dan komentar para mahasiswa semester 4 kelas A2 Universitas Muhammadiyah Tangerang program studi Pendidikan Bahasa dan Sastra Indonesia dalam media sosial whats app.Sumber data dalam penelitian ini adalah para mahasiswa/mahasiswi semester 4 kelas A2 Prodi Bahasa dan Sastra Indonesia Universitas Muhammadiyah Tangerang yang berusia 19-23 tahun dengan jumlah data sebanyak 6 mahasiswa/mahasiswi. Hasil penelitian ditemukan delapan kata bahasa prokem yaitu "Maaciw”, "Guy", "Mank”, “Tuman”, “Jan”, "KRS”, "Pap", dan "GC". Penggunaan bahasa prokem oleh mahasiswa semester 4 kelas A2 Universitas Muhammadiyah Tangerang sangat beragam berkaitan dengan akromin dan singkatan. Dampak penggunaan bahasa prokem yaitu 1) para mahasiswa memakai bahasa prokem yang tidak sesuai dengan kondisi maka akan menyulitkan lawan bicara, 2) bahasa prokem dapat menurunkan kualitas bahasa Indonesia, 3) Apabila digunakan terus menerus maka eksistensi bahasa Indonesi akan tergeser.
\end{abstract}

Kata Kunci: Bahasa Prokem, Whats App

\section{A. PENDAHULUAN}

Kalangan generasi muda yang menggunakan bahasa prokem dianggap modern dan eksistensinya sangat diapresiasi dari kalangan mereka sendiri. Pada era milenial saat ini, penggunaan bahasa prokem oleh remaja semakin banyak digunakan dalam proses berkomunikasi sehari-hari oleh generasi muda. Hal tersebut berdampak buruk pada eksistensi bahasa Indonesia kian menurun. Penggunaan bahasa prokem yang terus menurus membuat remaja sulit 
Lingua Rima: Jurnal Pendidikan Program Studi Bahasa dan Sastra Indonesia

Vol. 9 No. 1 Juli 2020

mengetahui tentang penggunaan bahasa Indonesia yang baik dan benar. Meski penggunaan bahasa prokem tidak dapat dihindari keberadaannya, tetapi jika hal itu terus terjadi akan menjadi kekhawatiran tersendiri.

Penggunaan bahas prokem juga dilakukan oleh para mahasiswa di kalangan Universitas Muhammadiyah Tangerang tidak hanya dalam percakapan sehari-hari. Mereka juga menggunakan bahasa prokem dalam konteks akademik misalnya presentasi, bertanya kepada dosen, menjawab pertanyaan dosen, maupun dalam menulis karya ilmiah. Bahasa prokem juga digunakan dalam percakapan tertulis di media sosial whats app. Penggunaaan bahasa prokem di kalangan mahasiswa kalangan Universitas Muhammadiyah Tangerang semakin beragam. Banyak muncul bahasa-bahasa yang baru, kemunculan bahasa tersebut sesuai dengan perkembangan trend yang ada di masyarakat.

Media sosial whats app merupakan media sosial yang digunakan untuk berkomunikasi secara daring. Beberapa tahun kebelakang, media sosial whats app menjadi media sosial terpopuler di Indonesia. Penggunaan whats app sangat mudah karena hanya dengan menyimpan nomor telephone, pengguna sudah langsung terhubung dengan pengguna lain. Bahasa yang digunakan di dalam media sosial whats app juga tidak jauh beda dengan SMS (Short Massage Service). Penggunaan bahasa dalam SMS lebih banyak menggunakan bahasa yang disingkat dan menggunakan bahasa prokem. Hal tersebut dikarenakan biaya pengiriman SMS dihitung sesuai dengan batas maksimal karakter. Satu karakter sekitar 100-150 huruf, dengan biaya antara 100350 rupiah. Hal tersebut, berpengaruh pada bahasa yang digunakan dalam media sosial whats app karena masyarakat terbiasa menggunakan SMS.

\section{B. KAJIAN PUSTAKA}

Bahasa prokem yang biasa digunakan oleh para remaja, memiliki perkembangan yang begitu cepat. Bahasa prokem awalnya hanya digunakan oleh kalangan preman yang digunakan sebagai kode rahasia atau kata sandi ketika mereka berkomunikasi agar isi dari pesan ketika mereka berkomunikasi tidak dapat dimengerti oleh orang lain.Seiring berkembangnya zaman, bahasa prokem semakin banyak digunakan oleh para remaja dalam berkomunikasi sehari-hari agar pesan yang ingin mereka sampaikan tidak dapat dimengeti terutama oleh orang tua dan guru mereka. Banyak media komunikasi yang menggunakan bahasa tersebut seperti media internet, televisi, radio, film, majalah, dan lain-lain. Hal tersebut berdampak bagi para remaja semakin mudah meniru dan menggunakan bahasa ketika berkomunikasi sehari-hari. 
Lingua Rima: Jurnal Pendidikan Program Studi Bahasa dan Sastra Indonesia

Vol. 9 No. 1 Juli 2020

Pengertian mengenai bahasa prokem Menurut Kridalaksana bahasa prokem adalah ragam nonstandar bahasa Indonesia yang lazim di Jakarta pada tahun 1970-an, kemudian digantikan oleh ragam yang disebut bahasa prokem (Kridalaksana, 2008: 28-29). Bahasa prokem adalah bahasa yang pertama kali digunakan oleh kalangan preman yang digunakan dalam proses berkomunikasi yang bertujuan agar tidak ada yang mengetahui isi dari percakapan mereka, dan seiring berkembangnya zaman bahasa prokem mulai banyak digunakan oleh para kalangan remaja baik di lingkungan keluarga, sosial, maappun lingkungan sekolah.

Biasanya bahasa prokem digunakan oleh para remaja agar kelompok lain tidak mengetahui isi dari percakapan yang sedang mereka bicarakan. Bahasa prokem juga muncul dan berkembang di kalangan remaja berdasarkan latar belakang sosial, budaya pemakainya, dan usia para remaja yang menggunakan bahasa tersebut. Kosakata yang digunakan dalam bahasa prokem biasanya muncul dan berkembang dari kosakata berdasarkan lingkungan tempat ia tinggal. Proses pembentukan kata serta makna yang terdapat dalam bahasa prokem tersebut tergantung pada kreativitas pemakainya, dan dapat juga kosakata bahasa prokem mengacu pada hal-hal dan masalah yang ada di sekitar rumah, perprokeman, pendidikan, dan kenakalan remaja yang biasa disebut dengan istilah kekerabatan.

Seiring berkembangnya zaman, bahasa prokem juga telah berkembang berdasarkan fungsinya sebagai bahasa sandi. Hal tersebut berdasarkan keinginan para remaja untuk berkomunikasi secara rahasia dengan disesuaikan dengan kesepakatan para remaja atau lawan bicaranya yang hendak menggunakan bahasa sandi tersebut. komunikasi menggunakan bahasa sandi ini sangat diperlukan oleh para remaja untuk menyampaikan pesan yang ingin disampaikan tanpa diketahui arti dan maksud dari percakapan oleh kelompok lain terutama oleh kalangan orang tua. Ragam bahasa prokem biasanya digunakan agar orang dari kelompok lain tidak dapat mengetahui apa yang sedang dibicarakan.

Pada saat ini banyak masyarakat khususnya remaja yang menggunakan bahasa prokem atau bahasa prokem dalam media sosial maappun percakapan sehari-hari. Pergeseran struktur kata yang terjadi pada masa sekarang dan dilakukan oleh banyak kalangan membuat muncul kosakata baru yang menggusur keformalan dalam berbahasa. Seperti pada kata "serius" berubah menjadi “ciyus", kata "beneran" berubah menjadi "enelan", kata "maaf” berubah menjadi "muapph", kata “iya" berubah menjadi "ea", kata "aku” berubah menjadi "aq" dan masih banyak lagi contohcontoh penggunaan bahasa prokem tersebut. 
Lingua Rima: Jurnal Pendidikan Program Studi Bahasa dan Sastra Indonesia

Vol. 9 No. 1 Juli 2020

Selain itu, penggunaan bahasa prokem di Indonesia cukap unik karena memiliki bentuk kosakata yang sangat bervariasi dengan jumlah yang cukapp banyak. Bahasa prokem juga digunakan sebagai bentuk pernyataan seorang remaja sebagai anggota kelompok masyarakat yang berbeda dari kelompok yang lain. Dengan hadirnya bahasa prokem yang berkembang pada saat ini dianggap sesuatu yang wajar karena sesuai dengan perkembangan usia remaja dan penggunaan bahasa prokem pun pada kalangan kelompok usia tertentu dan bersifat tidak resmi. Jika mereka berada di luar lingkungan kelompoknya, mereka akan menggunaan bahasa yang berlaku secara umum di lingkungan masyarakat tempat mereka berada dan jarang sekali yang tetap menggunakan bahasa prokem seperti di dalam kelompoknya.Bahasa prokem diciptakan melalui perubahan bentuk pesan Linguistik tanpa mengubah isinya untuk maksud penyembunyian atau kejenakaan. Jadi bahasa prokem hanya sebuah transformasi sebagian dari suatu bahasa menurut pola-pola tertentu. Bahasa berkembang maju secara perlaha sebagaimana manusia yang terus menurut mengalami perkembangan.

Penggunaan bahasa prokem juga merambah pada media sosial. Pada awalnya penggunaan bahasa prokem pada media social digunakan ketika adanya SMS atau Short Massange Service .SMS digunakan sebagai media berkirim pesan antara pengguna telepon genggam (HP).Oleh karena pada saat itu biaya berkirim pesan melalui SMS sangat mahal.Biaya SMS dibebankan dalam setiap karakter (huruf).Maka, para pengguna SMS harus dapat mengirimkan informasi melalui SMS secara singkat. Dampaknya penggunaan SMS cenderung membuat sebuah sandi atau kode dengan cara menghilangan beberapa huruf vokal maappun konsonan. Penggunaan huruf pada SMS berdampak hingga kini, ketika para pengguna SMS beralih pada media sosial.

Media sosial seperti whats app merappakan salah satu media sosial yang popular di kalangan generasi muda bahkan telah merambah pada generasi tua.Peranan media sosial whats app telah menggantikan posisi SMS yang pada saat itu menjadi salah satu media yang terpopular dalam media tulis online.Para generasi muda mengkreasikan bahasa-bahasa di media sosial whats appagar dianggap modern oleh sesama generasi muda.Sehingga mereka berlomba-lomba untuk menunjukkan eksistensi mereka.

\section{METODE PENELITIAN}

Jenis penelitian ini menggunakan metode analisis isi dengan pendekatan deskriptif kualitatif. Pendekatan deskriptif kualitatif dipilih karena peneliti berusaha menyajikan kenyataan-kenyataan secara objektif sesuai dengan kenyataan dalam bentuk kata ataappun 
Lingua Rima: Jurnal Pendidikan Program Studi Bahasa dan Sastra Indonesia

Vol. 9 No. 1 Juli 2020

kalimat yang ditemukan di lapangan tentang penggunaan bahasa prokem dalam media sosial whats app. Data yang digunakan dalam penelitian ini adalah data tulis yang berasal dari unggahan status dan komentar para mahasiswa semester 4 kelas A2 Universitas Muhammadiyah Tangerang program studi Pendidikan Bahasa dan Sastra Indonesia dalam media sosial whats app.Sumber data dalam penelitian ini adalah para mahasiswa/mahasiswi semester 4 kelas A2 Prodi Bahasa dan Sastra Indonesia Universitas Muhammadiyah Tangerang yang berusia 19-23 tahun dengan jumlah data sebanyak 6 mahasiswa/mahasiswi.

Teknik pengumpulan data yang digunakan dalam penelitian ini adalah teknik baca dan catat. Teknik analisis data pada penelitian ini yaitu dengan menggunakan 1) reduksi data yaitu peneliti melakukan pemilahan data mengenai penggunaan bahasa prokem dalam media sosial whats app mahasiswa semester 4 kelas A2 Universitas Muhammadiyah Tangerang program studi Pendidikan Bahasa dan Sastra Indonesia. 2) penyajian data yaitu peneliti menyajikan data mengenai penggunaan bahasa prokem dalam media sosial whats app mahasiswa semester 4 kelas A2 Universitas Muhammadiyah Tangerang program studi Pendidikan Bahasa dan Sastra Indonesia. 3) menyimpulkan yaitu peneliti melakukan penyimpulan mengenai penggunaan bahasa prokem dalam media sosial whats app mahasiswa semester 4 kelas A2 Universitas Muhammadiyah Tangerang program studi Pendidikan Bahasa dan Sastra Indonesia.

\section{PEMBAHASAN}

Berdasarkan penelitian yang dilakukan melalui proses pengamatan pada mahasiswa semester 4 kelas A2 Prodi Pendidikan Bahasa dan Sastra Indonesia Universitas Muhammadiyah Tangerang.Terdapat beberapa penggunaan bahasa prokem dalam media sosial whats app pada tabel berikut.

Tabel 1. Data Penelitian Bahasa Prokem dalam Media Sosial Whats App

\begin{tabular}{|l|l|l|}
\hline $\begin{array}{c}\text { Bahas Prokem } \\
\text { yang } \\
\text { Digunakan }\end{array}$ & \multicolumn{1}{|c|}{ Makna } & \multicolumn{1}{|c|}{ Pembetulan } \\
\hline Maaciw & Ungkapan rasa terima kasih & Terima kasih \\
\hline Guy & Panggilan kepada teman-teman & Teman-teman \\
\hline Mank & Pemendekkan dari kata emang & Emang \\
\hline Tuman & Bahasa daerah yang berarti kebiasaan & Kebiasaan \\
\hline Jan & Kependekan dari kata 'jangan' & Jangan \\
\hline
\end{tabular}


Lingua Rima: Jurnal Pendidikan Program Studi Bahasa dan Sastra Indonesia

Vol. 9 No. 1 Juli 2020

\begin{tabular}{|l|l|l|}
\hline KRS & Singkatan dari Kartu Rencana Studi & KRS \\
\hline Pap & Bahasa Inggris dari Post A picture & Foto \\
\hline GC & Singkatan dari kata 'Gerak Cepat' & Gerak Cepat \\
\hline
\end{tabular}

Data 1:

\section{lin}

\section{Maaciw 12.45}

Berdasarkan data 1 terdapat percakapan di komentar tersebut, terdapat kata"maaciw".kata "maaciw" tersebut berarti "terima kasih" dalam bahasa Indonesia yang baik dan benar. Penggunaan kata "maaciw" yang digunakan oleh Iin karena ia berkomunikasi dengan teman sebayanya menggunakan bahasa prokem atau bahasa prokem tetapi dengan menggunakan makna yang sama dengan makna terima kasih.

Data 2:

\section{Fibri}

\section{Tester dulu guys}

16.47

Berdasarkan percakapan data 2 di komentar tersebut, terdapat kata"tester dulu guys".kata "guys" tersebut memiliki makna sebagai kata ganti orang kedua (jamak) dan juga kata sapaan. Kata guys berasal dari bahasa inggris yang berarti kalian, kalian semua atau teman-teman. Penggunaan kata "guys" karena ia mengajak semua teman-temannya agar seorang yang berjualan memberikan sebuah percobaan sebelum membeli barang yang akan dijual oleh temannya.

Data 3 :

\section{Sasmita}

\section{Mank iya?}

Berdasarkan percakapan data 3 di komentar tersebut, terdapat kata"mank iya". Kata "mank" tersebut memiliki sebuah makna untuk menanyakan suatu kebenaran, dalam bahasa Indonesia kata tersebut bermakna "memang iya" . Kata "mank" merappakan sebuah 
Lingua Rima: Jurnal Pendidikan Program Studi Bahasa dan Sastra Indonesia

Vol. 9 No. 1 Juli 2020

pemendekan kata yang berasal dari kata "memang"digunakan oleh Sasmita. Pada hakikatnya, pemendekan kata merappakan proses penanggalan bagian-bagian leksem atau gabungan leksem sehingga menjadi sebuah bentuk singkat, tetapi maknanya tetap sama dengan makna utuhnya.

Data 4 :

\section{Diah}

\section{Tuman 18.30}

Berdasarkan percakapan data 4 di komentar tersebut, terdapat kata"tuman". Kata "tuman" belakangan ini banyak digunakan oleh para kaum milenial saat berkomunikasi, terutama di sosial media. Kata "tuman" menurut Kamus Besar Bahasa Indonesia memiliki makna menjadi biasa. Kata "tuman" memiliki makna yang sering dikenal pada saat ini yang berarti, terbiasa, selalu senang akan, ingin mengulangi lagi. Pada komentar "tuman" disini yaitu temannya memiliki sebuah kebiasaan yang selalu diulangi secara terus-menerus.

Data 5 :

\section{Anisa Jan lupa krs}

Berdasarkan percakapan data 5 di komentar tersebut, terdapat kata "jan lupa krs". Kata "jan lupa krs" merappakan sebuah pemendekan kata yang digunakan oleh Annisa ketika berkomunikasi dengan temannya. Kata "jan lupa krs" memiliki kata asli yaitu "jangan lupa kartu rencana studi”. Komentar ini memiliki makna untuk menyampaikan kepada teman-temannya agar jangan lappa mengumpulkan kartu rencana studi. Proses pemendekan kata pada dasarnya dapat digunakan oleh siapa saja dan kapan saja tetapi harus sesuai dengan situasi dan kondisi tertentu.

Data 6:

\section{Njum}

Coba pap 08.02

Buat bukti

Berdasarkan komentar percakapan di komentar tersebut, terdapat kata "Pap". Kata "Pap" merupakan sebuah pemendekan kata ketika berkomunikasi dengan temannya. Kata "Pap" memiliki kata asli dalam bahasa Inggris yaitu Post A picture. Komentar yang disampaikan 
Lingua Rima: Jurnal Pendidikan Program Studi Bahasa dan Sastra Indonesia

Vol. 9 No. 1 Juli 2020

memiliki makna untuk menyampaikan kepada teman-temannya agar mengirimkan bukti berapa foto agar dapat membuktikan hal tersebut benar-benar terjadi. Kata "pap" ini biasanya dipakai oleh seorang kaum remaja karena mereka lebih nyaman menggunakan kata"pap" dibandingkan dengan "coba foto"

\section{Data 7:}

\section{Aeni \\ Gc}

Berdasarkan percakapan di komentar tersebut, terdapat kata "Gc". Kata "Gc" merappakan sebuah pemendekan kata yang digunakan oleh Aeni ketika berkomunikasi dengan temannya. Kata "GC" memiliki kata asli dalam bahasa Indonesia yaitu Gerak Cepat. Komentar ini memiliki makna untuk menyampaikan kepada teman-temannya agar dapat melakukan suatu aktivitas secara cepat dan agar tidak terlalu lama mengulur waktu.

Penggunaan bahasa prokem juga tidak bisa dihindari, karena biasanya digunakan untuk berkomunikasi di lingkungan sosial dan juga termasuk variasi bahasa Indonesia yang ada saat ini. Namun pada saat ini, banyak remaja yang tidak memakai bahasa Indonesia yang baik dan benar dan mereka lebih gemar untuk menggunakan bahasa prokem ketika mereka berkomunikasi satu sama lain. Terdapat beberapa dampak yang muncul dari penggunaan bahasa prokem itu sendiri, yaitu :

a. Bahasa prokem jika pemakaiannya tidak disesuaikan dengan situasi dan kondisi akan mempersulit proses berkomunikasi jika lawan bicara tidak mengerti bahasa tersebut.

b. Bahasa prokem dapat menyebabkan penurunan kualitas penggunaan bahasa Indonesia di kalangan remaja pada saat ini maupun dimasa yang akan datang, karena mereka terbiasa menggunakan bahasa prokem sehingga mereka lupa tentang penggunaan bahasa Indonesia yang baik dan benar.

c. Penggunaan bahasa prokem secara terus menerus, dapat menggeser eksistensi bahasa Indonesia jika ini tidak segera disadari.

Bahasa prokem atau yang lebih dikenal sebagai bahasa prokem memiliki sifat informal serta tidak dapat digunakan dalam acara formal atau resmi yang membutuhkan penggunaan bahasa Indonesia yang baik dan benar. Pada saat ini bahasa prokem merupakan bahasa yang secara tidak langsung dapat mengubah tata bahasa Indonesia. Jika hal ini terus berlangsung, 
penggunaan bahasa prokem yang lebih mendominasi daripada penggunaan bahasa Indonesia baku. Tentu saja hal tersebut dapat menimbulkan kekhawatiran kita sebagai bangsa Indonesia, karena kaum remaja merupakan para penerus bangsa di masa yang akan datang. Jika mereka tidak mengenali atau mengetahui penggunaan bahasa Indonesia yang baik dan benar bukan tidak mungkin penutur bahasa Indonesia akan bekurang suatu saat nanti.

Oleh karena itu kesadaran masyarakat harus dibuka lebih lebar lagi agar mereka dapat mengutamakan penggunaan bahasa Indonesia dan menggunakan bahasa prokem sesuai dengan situasi dan kondisinya. Jangan sampai bahasa prokem lebih mendominasi penggunaannya daripada bahasa Indonesia. Karena bahasa Indonesia merappakan identitas bangsa Indonesia dan kita sebagai penerus bangsa harus menjunjung tinggi bahasa nasional. Kesadaran tersebut harus kita tanam mulai dari diri kita sendiri, sehingga dapat menular dan berkembang ke masyarakat luas.

\section{E. SIMPULAN}

Bahasa prokem selalu berkembang dari waktu kewaktu, itu berarti akan muncul jenisjenis bahasa prokem baru. Penggunaan bahasa prokem yang disisipkan dalam bahasa Indonesia ketika proses berkomunikasi adalah salah satu cara untuk membuat komunikasi menjadi semakin cepat dan sederhana. Penggunaan bahasa prokem di media sosial Whatsapp dilakukan oleh seluruh mahasiswa kelas 4.A2 Prodi Bahasa dan Sastra Indonesia Universitas Muhammadiyah Tangerang. Penggunaan bahasa prokem atau bahasa prokem yang digunakan di sosial media Whatsapp terdapat bahasa prokem atau bahasa prokem yang dalam proses pembentukannya melalui cara afiksasi, memberi suatu sisipan, atau pemendekan kata. Sementara itu, arti atau makna yang terkandung masih dapat dimengerti oleh bicaranya. Bahasa prokem biasanya digunakan oleh kaum remaja untuk berkomunikasi dengan teman sebaya atau berada di lingkungan yang mengetahui arti dan makna dari bahasa prokem tersebut. 
Lingua Rima: Jurnal Pendidikan Program Studi Bahasa dan Sastra Indonesia

Vol. 9 No. 1 Juli 2020

\section{Daftar Pustaka}

Gantamitreka, shokha. 2016.Kesalahan Berbahasa Pengguna EYD.Solo. Genta Smart Publish.

Kridalaksana, Harimurti. 2008. Kamus Linguistik Edisi keempat. Jakarta: PT.Gramedia.

Sartuni, Rasyid. 2007.Aplikasi Bahasa Akademik. Jakarta: Cv Alfonso Pratama

Soeparno. 199. Dasar-Dasar Linguistik. Yogyakarta: Mitra Gama Widya.

Subroto, Edi.2011. Pengantar Studi Semantik dan Prakmatik. Kadipiro Surakarta:Cakrawala Media.

Sumarsono, 2014. Sosiolinguistik. Yogyakarta: SABDA (Lembaga Studi Agama, Budaya dan Perdamaian).

Wijanna, I Dewa Putu, dan Muhammad, Rohmadi. 2013. Sosiolingustik Kajian Teori dan Analisis. Cileban Timur Yogyakarta: pustaka Pelajar

Zul, Eka.2009: "Pemakaian Bahasa Prokem”. http://id.wikipedia.org/wiki/Bahasa Prokem Indonesia/. 